\title{
Triple therapy with scopolamine, ondansetron, and dexamethasone for prevention of postoperative nausea and vomiting in moderate to high-risk patients undergoing craniotomy under general anesthesia: a pilot study
}

OPEN ACCESS

Edited by:

Radmilo J. Jankovic,

University of Niš, Serbia

Reviewed by:

Ohta Yoshinori,

Hyogo College of Medicine, Japan

Ivan Velickovic,

SUNY Downstate Medical Center,

USA

Massimiliano Sorbello,

AOU Policlinico Vittorio Emanuele

Catania, Italy

*Correspondence:

Alberto A. Uribe,

Department of Anesthesiology, The Ohio State University Wexner Medical

Center, 410 West 10th Avenue,

Columbus, OH 43210, USA

alberto.uribe@osumc.edu

Specialty section:

This article was submitted to Intensive Care Medicine and Anesthesiology,

a section of the journal Frontiers in

Medicine

Received: 22 April 2015

Accepted: 24 May 2015

Published: 15 June 2015

Citation:

Bergese SD, Antor MA, Uribe AA, Yildiz V and Werner J (2015) Triple therapy with scopolamine,

ondansetron, and dexamethasone

for prevention of postoperative nausea and vomiting in moderate to

high-risk patients undergoing craniotomy under general anesthesia: a pilot study.

Front. Med. 2:40

doi: 10.3389/fmed.2015.00040

\author{
Sergio D. Bergese ${ }^{1,2}$, Maria A. Antor ${ }^{3}$, Alberto A. Uribe $^{1 *}$, Vedat Yildiz $^{4}$ and \\ Joseph Werner ${ }^{1}$
}

\begin{abstract}
'Department of Anesthesiology, The Ohio State University Wexner Medical Center, Columbus, OH, USA, ${ }^{2}$ Department of Neurological Surgery, The Ohio State University Wexner Medical Center, Columbus, OH, USA, ${ }^{3}$ Department of Anesthesiology, Jackson Memorial Hospital, University of Miami, Miami, FL, USA, ${ }^{4}$ Center for Biostatistics, The Ohio State University, Columbus, $\mathrm{OH}$, USA
\end{abstract}

Introduction: Postoperative nausea and vomiting (PONV) is one of the most common complaints from patients and clinicians after a surgical procedure. According to the current Society of Ambulatory Anesthesia Consensus Guidelines, the general incidence of vomiting and nausea is around 30 and $50 \%$, respectively; and up to $80 \%$ in high-risk patients. In previous studies, the reported incidence of PONV at $24 \mathrm{~h}$ after craniotomy was $43-70 \%$. The transdermal scopolamine (TDS) delivery system contains a 1.5-mg drug reservoir, which is designed to deliver a continuous slow release of scopolamine through intact skin during the first $72 \mathrm{~h}$ of patch application. Therefore, we designed this single arm, non-randomized, pilot study to assess the efficacy and safety of triple therapy with scopolamine, ondansetron, and dexamethasone to prevent PONV.

Materials and methods: In the preoperative area, subjects received an active TDS $1.5 \mathrm{mg}$ that was applied to a hairless patch of skin in the mastoid area approximately $2 \mathrm{~h}$ prior to the operation. Immediately after anesthesia induction, all patients received a single $4 \mathrm{mg}$ dose of ondansetron IV and a single $10 \mathrm{mg}$ dose of dexamethasone IV. Patients who experienced nausea and/or vomiting received ondansetron $4 \mathrm{mg} I \mathrm{~V}$ as the initial rescue medication. Postoperative nausea and vomiting assessments were performed for up to $120 \mathrm{~h}$ after surgery.

Results: A total of 36 subjects were analyzed. The overall incidence of PONV during the first $24 \mathrm{~h}$ after neurological surgery was 33\% ( $n=12)$. The incidence of nausea and emesis during the first $24 \mathrm{~h}$ after surgery was recorded as 33\% $(n=12)$ and $16 \%(n=6)$, respectively.

Conclusion: Our data showed that this triple therapy regimen may be an efficient alternative regimen for PONV prophylaxis in patients undergoing neurological surgery with general anesthesia. Further studies using regimens affecting different receptor pathways should be performed to better prove the efficacy and safety in the prevention or delay of PONV.

Keywords: nausea, vomiting, scopolamine, postoperative care, ondansetron 


\section{Introduction}

Postoperative nausea and vomiting (PONV) is one of the most common concerns from subjects and clinicians after a surgical procedure (1). The literature defines PONV as the presence of nausea and vomiting during the first 24 hours after a surgical procedure. PONV can be classified as either early PONV $(0-2$ hours (h)) or delayed PONV (2-24h) (1). Episodes that occur after the patient has left the institution are known as post-discharge nausea and vomiting (PDNV) $(1,2)$. According to the 2014 consensus guidelines for the management of PONV from the Society of Ambulatory Anesthesia (SAMBA), the general incidence of vomiting and nausea is around 30 and $50 \%$, respectively; and up to $80 \%$ in high-risk patients (three and more risk factors) (1). The increase in central venous pressure (CVP) that results from the act of retching can lead to potentially severe complications in certain surgical populations. For instance, in craniotomy patients, this increase in CVP could presumably lead to postoperative intracranial hemorrhage or worsening of intracranial pressure (3). In previous studies, the reported incidence of PONV at $24 \mathrm{~h}$ after craniotomy was $43-70 \%(4-7)$.

Ondansetron is a serotonin (5HT3) receptor antagonist most used in PONV trials and is considered the "gold standard" antiemetic due to its efficacy and low cost $(1,6,9,10,14-18)$. This drug's short half-life of around $4 \mathrm{~h}$ and its lack of sedative effect make it an excellent option in the neurosurgical field $(1,4,10)$. The corticosteroid dexamethasone is another medication widely used for PONV prophylaxis; its intravenous (IV) administration after anesthesia induction is recommended, and it has similar efficacy for PONV prophylaxis as ondansetron (1, 4). Scopolamine is considered a non-polar, tertiary amino compound, and muscarinic acetylcholine antagonist. As part of its pharmacodynamic properties, it has an adequate absorption in the gastrointestinal tract and excellent blood-brain barrier penetration. Scopolamine has also been reported to be effective in the prevention of PONV (1, 2, 5, 10, 15, 17, 19-22). The literature showed that IV or intramuscular scopolamine has a short halflife in plasma and may lead to dose-dependent side effects such as excessive drowsiness, agitation, hallucinations, dizziness, dry mouth, and lethargy. Conversely, transdermal scopolamine (TDS) releases the drug over a period of $72 \mathrm{~h}$; for this reason, the risks of plasma concentration-related side effects may be lower due to the slower rate of transdermal absorption (10). TDS contains a $1.5-\mathrm{mg}$ drug reservoir, which is intended to supply a continuous slow release of scopolamine through intact skin during the first $72 \mathrm{~h}$ of patch application (23). The U.S. Food and Drug Administration (FDA) approved the TDS in 1979 as a method of motion sickness prophylaxis; then, in 2001, it was approved for PONV prophylaxis (2). PDNV usually remains as unreported events due to early discharge despite the fact that it is usually documented by many patients as the most undesirable postoperative event (2, 24). TDS is designed to deliver a constant rate of approximately $1.0 \mathrm{mg}$ of scopolamine into the systemic circulation over $72 \mathrm{~h}$ and thus may play an important role to prevent PDNV since it is designed to deliver scopolamine for $72 \mathrm{~h}$. Multiple studies using TDS for prophylaxis did not assess PONV $24 \mathrm{~h}$ after surgery, thus data supporting the antiemetic effects for delayed PONV are lacking $(5,19,20,22,25)$. Considering the beneficial effects of TDS, its favorable pharmacokinetic and pharmacodynamic profile, and the importance of PONV prophylaxis, TDS may turn into a strong alternative to be one of the first or second line therapeutic agents for PONV (2). The efficacy of TDS in PONV prophylaxis is well-established in different studies $(1,5,9,15,19$ $22,26)$. However, the use of TDS in the neurosurgical field has not been studied before, probably due to its controversial sedative side effect and the rare possibility of untoward physical exam findings from this anticholinergic medication (e.g., dilated pupils) (2). Therefore, we designed this single arm, non-randomized, pilot study to assess the efficacy and safety of triple therapy with scopolamine, ondansetron, and dexamethasone to prevent PONV. We hypothesized that prophylactic triple therapy with scopolamine, ondansetron, and dexamethasone was an effective and safe treatment for the prevention of PONV in patients with moderate to high risk of PONV who underwent neurological surgery under general anesthesia (27).

\section{Materials and Methods}

After obtaining institutional review board (Office of Responsible Research Practices) approval for the research protocol, a total of 44 subjects provided their written informed consent before any study-specific procedures were done at The Ohio State University Wexner Medical Center. Study inclusion criteria consisted of neurosurgical subjects scheduled to undergo elective craniotomy (opening of the cranium and Dura mater) requiring at least $1 \mathrm{~h}$ of general anesthesia with an expected $24 \mathrm{~h}$ hospitalization. These subjects had moderate to severe risk for PONV as assessed by having two or more risk factors on the simplified Apfel score. Exclusion criteria consisted of prisoner status, medical history of alcohol or drug abuse, history of allergic reaction or intolerance to any study medications, pregnant or breastfeeding female subjects, history of nausea and/or vomiting within $24 \mathrm{~h}$ prior craniotomy, history of treatment with antiemetic medication for nausea or vomiting within $24 \mathrm{~h}$ of their procedure, and history of chemotherapy treatment within 4 weeks prior to surgery. Subjects who had received any medication with antiemetic properties were also excluded from participating in the study.

Prior to surgery, vitals and study safety procedures including electrocardiogram (ECG) and a urine or serum pregnancy test were performed. In the preoperative area, subjects received an active TDS $1.5 \mathrm{mg}$ that was applied to a hairless patch of skin in the mastoid area approximately $2 \mathrm{~h}$ prior to the operation. Immediately after anesthesia induction, all subjects received a single $4 \mathrm{mg}$ dose of ondansetron IV and a single $10 \mathrm{mg}$ dose of dexamethasone IV.

The standardized anesthesia regimen also consisted of premedication of midazolam 1-2 mg IV immediately before transferring the subjects to the operating room. Anesthesia was induced with propofol $1-2 \mathrm{mg} / \mathrm{kg}$ IV and fentanyl $0.75-1.5 \mu \mathrm{g} / \mathrm{kg}$ IV. Tracheal intubation was performed after the administration of rocuronium $0.6-1.2 \mathrm{mg} / \mathrm{kg}^{-1} \mathrm{IV}$.

General anesthesia was maintained with volatile anesthetics (sevoflurane, desflurane, or isoflurane) and its titration concentration was guided on clinical judgment. Analgesia during 
anesthesia maintenance was provided with fentanyl boluses of $0.5-2.0 \mu \mathrm{g} / \mathrm{kg}^{-1} \mathrm{IV}$. At the end of the procedure, neostigmine and glycopyrrolate were used to reverse residual neuromuscular block.

After surgery, subjects were transferred to the surgical intensive care unit (SICU) or post anesthesia care unit (PACU); subjects that experienced nausea and/or vomiting received ondansetron $4 \mathrm{mg}$ IV as the initial rescue medication for PONV. Choice of subsequent rescue antiemetic was left to the anesthesiologist's discretion.

This pilot study explored the effects of TDS triple therapy on PONV $24 \mathrm{~h}$ postoperative as a primary endpoint. As such, TDS was removed by the study investigators $24 \mathrm{~h}$ after the end of surgery (defined as discontinuation of the inhaled anesthetic). If the patch became dislodged from the skin during the first $24 \mathrm{~h}$ after surgery, study investigators reapplied in the same site and covered with a bandage. Anesthesia and surgical procedure start and end time, admission and discharge time from the PACU, SICU, general care floor, total length of stay, and preoperative Apfel score were recorded. As a secondary outcome, the influence of this triple therapy administration on delayed PONV was assessed every $24 \mathrm{~h}$ for 5 days via direct interview and/or medical records review. Intraoperative medication and opioid daily consumption from PACU arrival time through a 5-day follow up were recorded.

First episode of nausea, vomiting, and rescue medication were recorded. Nausea was assessed by asking subjects to rate their nausea on a $0-10$ point scale, with 0 being no nausea at all and 10 being severe nausea. Vomiting was assessed by asking subjects to rate their vomiting on a $0-3$ point scale, with 0 being no vomiting, 1 being mild vomiting (1-2 episode in $12 \mathrm{~h}$, small amount of emesis), 2 being moderate vomiting (3-5 episodes in $12 \mathrm{~h}$, breakthrough vomiting), and 3 being severe vomiting (6-7 episodes in $12 \mathrm{~h}$, intractable, incessant, projectile).

For subjects discharged before the end of a 5-day time period, telephone contact was performed every $24 \mathrm{~h}$ to assess nausea and/or vomiting, rescue medication, opioid consumption, as well as adverse events and serious adverse events. Following the first $24 \mathrm{~h}$ after administration of the prophylactic triple therapy, an ECG was performed as part of safety assessments.

\section{Results}

A total of 44 subjects were enrolled in the study, 6 were considered screen failures, and 2 were early terminations. Thus, the data from 36 subjects were analyzed. The primary reason for screen failure was failure to meet all of the inclusion/exclusion criteria $(n=6)$. One subject was excluded from the study due to the surgeon's decision to remove the TDS before surgery and another due to change in the surgical procedure from craniotomy to craniectomy (Figure 1).

Subjects were further analyzed based on whether or not they experienced any nausea during the first $120 \mathrm{~h}$ after the surgery. The subjects demographic's, Apfel risk factors for PONV, duration of anesthesia, duration of PACU stay, duration of SICU stay, duration of total hospital stay, and postoperative opioid consumption are listed in Table 1. No adverse events related to the study medications were observed.

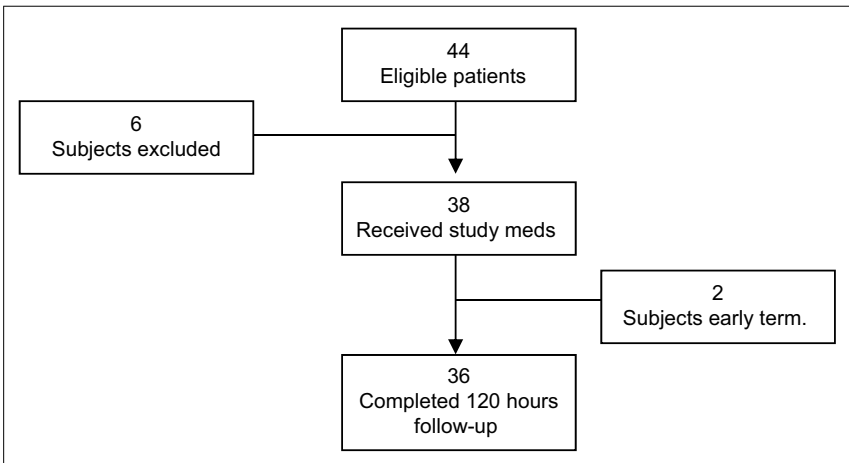

FIGURE 1 | Patient screening flowchart.

TABLE 1 | Patient demographics and surgical variables.

Demographics and surgical variables

Scopolamine

group $(n=36)$

Age, mean (SD), years

48 (14.6)

Weight, mean (SD), kg

$82(20.4)$

Height, mean (SD), cm

169 (9.6)

$\mathrm{BMI}$, mean (SD)

ASA I/II/III

Race-White, $n$ (\%)

29 (8.2)

$1 / 11 / 24$

$29(80)$

22 (61)

Sex (female) $n$ (\%)

33 (92)

(\%)

$\begin{array}{lc}\text { History of PONV and/or motion of sickness } n(\%) & 12(33) \\ \text { Postoperative opioids, } n(\%) & 36 \text { (100) }\end{array}$

Apfel risk factors, $n(\%)$

2

3

$13(36.1)$

$15(42.0)$

$8(22.0)$

Duration of anesthesia, mean (SD), hours

$5(2.8)$

$2(1.0)$

Duration of PACU stay, mean (SD), hours

$2(2.3)$

3 (3)

Duration of total hospital stay, mean (SD), days

$66(41-154)$

morphine, mg

Postoperative opioid consumption 0-48, media (IQR) oral

$123(45-241)$

morphine, mg

Postoperative opioid consumption 0-120, media (IQR) oral 228 (48-416) morphine, mg

The overall incidence of PONV during the first $24 \mathrm{~h}$ after craniotomy was $33 \%(n=12)$. The incidence of nausea and emesis during the first $24 \mathrm{~h}$ after surgery was recorded as $33 \%(n=12)$ and $16 \%(n=6)$, respectively. The percentage of subjects with freedom from emesis episodes over $0-24 \mathrm{~h}$ postoperatively was $84 \%$ ( $n=30,83 \% \mathrm{CI} ; 67-93 \%)$. Of those that experienced nausea during the first $24 \mathrm{~h}$ after neurological surgery, the median severity was rated as 8.5 (5.5-10). The median severity of vomiting was 2 (1-2), corresponding to moderate severity. Rescue medication during the first $24 \mathrm{~h}$ was used in 11 subjects (30\%). The complete response and control rate during the first $24 \mathrm{~h}$ as $69 \%(n=25,95 \%$ CI: 53-84\%) (Table 2).

The mean time to first emetic episode, first rescue, and first significant nausea was $26.7( \pm 30.2), 19.6( \pm 24.1), 23.6( \pm 27.1)$ hours, respectively (Table 3). 
TABLE 2 | Postoperative nausea and vomiting outcome variables $(n=36)$

\begin{tabular}{|c|c|c|c|c|c|c|c|c|c|c|c|c|}
\hline \multirow[t]{2}{*}{ Outcome variables } & \multicolumn{2}{|c|}{$0-2 h$} & \multicolumn{2}{|c|}{$0-24 h$} & \multicolumn{2}{|c|}{$24-48 h$} & \multicolumn{2}{|c|}{ 24-72h } & \multicolumn{2}{|c|}{ 24-96h } & \multicolumn{2}{|c|}{ 24-120h } \\
\hline & $N$ & $\%$ & $N$ & $\%$ & $N$ & $\%$ & $N$ & $\%$ & $N$ & $\%$ & $N$ & $\%$ \\
\hline Freedom from emesis & 35 & 98 & 30 & 84 & 33 & 92 & 32 & 89 & 31 & 86 & 30 & 84 \\
\hline Vomiting & 1 & 2 & 6 & 16 & 3 & 8 & 4 & 11 & 5 & 14 & 6 & 16 \\
\hline Number of vomiting episodes (IQR) & \multicolumn{2}{|c|}{$2(2,2)$} & \multicolumn{2}{|c|}{$1.5(1,3)$} & \multicolumn{2}{|c|}{$1(1,4)$} & \multicolumn{2}{|c|}{$1.5(1,3)$} & \multicolumn{2}{|c|}{$1(1,4)$} & \multicolumn{2}{|c|}{$1(1,4)$} \\
\hline Vomiting severity (IQR) & \multicolumn{2}{|c|}{$2(2,2)$} & \multicolumn{2}{|c|}{$2(1,2)$} & \multicolumn{2}{|c|}{$3(2,3)$} & \multicolumn{2}{|c|}{$2.5(2,3)$} & \multicolumn{2}{|c|}{$2(2,3)$} & \multicolumn{2}{|c|}{$2.5(2,3)$} \\
\hline Nausea & 4 & 11 & 12 & 33 & 8 & 22 & 12 & 33 & 14 & 38 & 14 & 38 \\
\hline Number of nausea episodes (IQR) & \multicolumn{2}{|c|}{$2(1.5,2.5)$} & \multicolumn{2}{|c|}{$2(1.5,3)$} & \multicolumn{2}{|c|}{$2(1,4.5)$} & \multicolumn{2}{|c|}{$1(1,2)$} & \multicolumn{2}{|c|}{$3.5(1,6)$} & \multicolumn{2}{|c|}{$3.5(1,8)$} \\
\hline Worst nausea score (IQR) & \multicolumn{2}{|c|}{$6(5.5,8)$} & \multicolumn{2}{|c|}{$8.5(5.5,10)$} & \multicolumn{2}{|c|}{$7.5(5,10)$} & \multicolumn{2}{|c|}{$7(5,9.5)$} & \multicolumn{2}{|c|}{$7(5,9)$} & \multicolumn{2}{|c|}{$7(5,9)$} \\
\hline Complete control & 32 & 89 & 25 & 69 & 32 & 89 & 30 & 83 & 28 & 78 & 27 & 75 \\
\hline Complete response & 32 & 89 & 25 & 69 & 32 & 89 & 30 & 83 & 28 & 78 & 27 & 75 \\
\hline Number of rescue therapy & 4 & 11 & 11 & 30 & 2 & 5 & 3 & 8 & 4 & 9 & 4 & 9 \\
\hline
\end{tabular}

Complete control $=$ no emesis + no rescue medication + no nausea $>4$ (0-10 scale).

Complete response $=$ no emesis + no rescue medication.

TABLE 3 | Intent to treat population.

Time to treatment failure, mean (SD)

Time hours

Scopolamine $(n=36)$

Time to first emetic episode

Time to first rescue

$26.7(30.2)$

$19.6(24.1)$

Time to first significant nausea

$23.6(27.1)$

95\% Confidence interval for complete response (0-24 h): [0.53, 0.84].

The cumulative overall incidence of PONV during the delayed period $(24-120 \mathrm{~h})$ was $38 \%(n=14)$. The incidence of nausea and emesis during $24-120 \mathrm{~h}$ after surgery was recorded as $38 \%$ $(n=14)$ and $16 \%(n=6)$, respectively. The percentage of subjects with freedom from emesis episodes over $24-120 \mathrm{~h}$ postoperative was $84 \%(n=30,83 \% \mathrm{CI} ; 67-93 \%)$. Of those that experienced nausea during $24-120 \mathrm{~h}$ after neurological surgery, the median severity was rated as $7(5,9)$. The median severity of vomiting was $1(1,4)$, corresponding to mild severity. Rescue medication during 24-120 h was used in 4 subjects (9\%). The complete response and complete control rate during $24-120 \mathrm{~h}$ was $75 \%(n=27,95 \% \mathrm{CI}$ : 74-96\%).

The median number of vomiting episodes from 0 to $120 \mathrm{~h}$ postoperative ranged between 1 and 1.5 (Table 2).

\section{Discussion}

The results of this study demonstrated that the combined use of TDS, ondansetron, and dexamethasone was an effective therapy to prevent nausea and vomiting in subjects undergoing craniotomy using general anesthesia. This prospective pilot study analyzed the data of 36 subjects that underwent craniotomy; postoperative nausea and vomiting assessments were performed for up to $120 \mathrm{~h}$ after surgery.

There is not a single risk factor for PONV that is sensitive or specific enough to be used alone to assess the risk of PONV.

However, one can combine multiple independent predictors using the simplified risk score model from Apfel et al. to help stratify a patient's risk for PONV (8). The risk factors from the simplified risk score model are female gender, smoking status, postoperative opioid consumption, and a history of PONV/PDNV or motion sickness (8). Each factor has a value of 1 , which gives a range of 0-4 when added together, 0 being low-risk and 4 signaling high-risk patients $(1,8-10)$. The SAMBA Consensus Guidelines for the Management of PONV recommend assessing patient's risk factors and providing treatment to prevent PONV. In addition, SAMBA recommends prophylactic combined therapy in subjects with moderate and high risk for $\operatorname{PONV}(1,11)$. Considering the potentially catastrophic effects of vomiting on intracranial pressure and postoperative hemorrhage for post-craniotomy patients, a long-lasting antiemetic profile might be favorable for postoperative patient care and may diminish post-surgical complications $(4,12,13)$. The Apfel scale predicts a PONV incidence of $60-80 \%$ in subjects with moderate to severe risks (8). However, our study reported a PONV incidence of 33\%; these results support our hypothesis that application of TDS within $2 \mathrm{~h}$ prior to surgery and the IV administration of ondansetron and dexamethasone immediately after anesthesia induction is an alternative regimen to reduce the incidence of $\mathrm{PONV}$ in subjects undergoing craniotomy under general anesthesia.

The literature describes adverse events associated with the use of TDS as generally mild $(1,2,21,27)$. The most frequent adverse event reported is dryness of mouth (29-91\%); and other less common drug reaction are drowsiness $(<16.6 \%)$, dizziness $(8-12 \%)$, blurred vision $(<8 \%)$, and disorientation $(<1 \%)(1,2,21,27)$. The results from our study did not show significant incidence of any of the most common adverse events related with TDS; particularly dry mouth, which is a symptom that could be difficult to assess in neurosurgical settings and commonly reported preoperatively settings as well (21). In addition, our results showed that the administration of this prophylactic regimen did not significantly increase the QTc interval in the ECGs. 
TABLE 4 | Apfel comparison in PONV $24 \mathrm{~h}$ : literature versus our findings

\begin{tabular}{lrrccc}
\hline $\begin{array}{l}\text { Apfel risk } \\
\text { factor }\end{array}$ & $\boldsymbol{N}$ & PONV 24h & $\begin{array}{l}\text { PONV 24h } \\
\text { (Apfel) (\%) }\end{array}$ & $\boldsymbol{p}$-Value & $\mathbf{C l}$ \\
\hline 2 & & & 40 & 0.071 & {$[0.04,0.42]$} \\
3 & $13(36.1 \%)$ & $2(15.4 \%)$ & 60 & 0.008 & {$[0.11,0.52]$} \\
4 & $15(41.7 \%)$ & $4(26.7 \%)$ & 80 & 0.723 & {$[0.41,0.92]$} \\
\hline
\end{tabular}

The incidence of PONV in patients with three Apfel's risk factors is $60 \%$ (recorded in the literature) (8) and our results showed an incidence of only $26.7 \%$ (8) (Table 4). Gan et al. confirmed the effectiveness of TDS with data collected from 0 to $48 \mathrm{~h}$ postoperative; they included one of the largest sample size populations to date (10). The study assessed the effectiveness of the use of TDS plus ondansetron compared with a placebo patch plus ondansetron as a preventing treatment for PONV in approximately 620 female patients that underwent outpatient laparoscopic or breast augmentation procedures (10). This study found a significant reduction in PONV $24 \mathrm{~h}$ after surgery in the group who received a combination of TDS and ondansetron; $48 \%$ of subjects that received a combination of TDS and ondansetron and 39\% that received only ondansetron did not experience vomiting and did not require rescue medication (10). Even TDS has a slow onset of action, this study showed that clinical benefits seem when TDS is applied $2 \mathrm{~h}$ before induction of anesthesia when it is used in a combination with ondansetron (10). In addition, this trial reported that the overall incidence of adverse events was less frequent in the group receiving TDS in combination with ondansetron compared with the group receiving ondansetron alone (10).

Latz et al. presented a prospective study that evaluated the incidence and risks factors of PONV in 229 subjects after craniotomies (5). They found an incidence of PONV during the first $24 \mathrm{~h}$ after surgery of $47 \%$ and identified absence of intraoperative steroids as a risk factor (5). In our study, the use of dexamethasone as a potent antiemetic on the triple therapy on subjects after craniotomy reduced PONV considerably.

Lee HK et al. demonstrated that the combination of TDS plus dexamethasone was more effective in complete remission of PONV compared with dexamethasone alone or dexamethasone plus ramosetron ( 82.5 versus 47.5 , and $50.0 \%$, respectively) in 120 subjects who underwent major orthopedic surgery with patientcontrolled analgesia via epidural route (15). A few limitations of this study included the lack of a control-group without prophylaxis, PONV assessments were performed only for $24 \mathrm{~h}$ after surgery and all subjects had an indwelling urinary catheter; thus, the side effect of TDS on urinary retention was not assessed $(15,16)$.

Habib et al. designed a study comparing the combination of aprepitant and dexamethasone versus ondansetron and dexamethasone for PONV prophylaxis in subjects that underwent craniotomy (4). They reported an accumulative incidence of PONV during the first $24 \mathrm{~h}, 36 \%$ with ondansetron and $14 \%$ with aprepitant. However, the difference of nausea and rescue medication was not statistically significant (4).
Lee et al. designed a similar randomized study that assessed the efficacy of the administration of TDS and ondansetron IV to prevent nausea after uterine artery embolization compared with ondansetron IV alone (16). Overall, the incidence of nausea after this procedure was low; there was a lower level of nausea with those treated with TDS compared with placebo during the first $24 \mathrm{~h}$ after embolization (16). Adverse events were more common in the TDS group, with two subjects experiencing episodes of profound disorientation and $71 \%$ reported considerable dry mouth (16). Their results showed that TDS offers moderate reduction of nausea; but, it was associated with occasional but notable episodes of disorientation. Therefore, according to their findings, the decision of using TDS should be based on careful consideration of the potential benefits and undesirable side effects (16). No adverse events associated with scopolamine were found (16).

The literature reported an incidence of nausea after craniotomy considerably variable, ranging from 43 to $70 \%$ (4-7) and vomiting from $33 \%(28)$ to $55 \%(5)$. In another study designed by Fabling et al., a randomized double blinded study compared ondansetron, droperidol, and placebo after supratentorial craniotomy showed that the incidence of PONV during the first $24 \mathrm{~h}$ was 35,30 , and $70 \%$, respectively (6).

Our study had its limitations that should be considered. First, it was a pilot study with the analysis of 36 subjects with no control group. Its primary objective was the assessment of efficacy and safety of triple therapy with TDS in craniotomies. Second, ondansetron was administered during induction of anesthesia as recommended in the package insert rather than used at the end of surgery as suggested by the latest PONV guidelines (1). Third, all subjects left the operation room with an indwelling urinary catheter, and thus the effects of TDS on urinary retention could not be assessed. In addition, TDS was removed 24 $\mathrm{h}$ after the end of surgery; future studies should maintain the TDS for $72 \mathrm{~h}$ and assess efficacy for PONV and PDNV. In addition, we acknowledge another crucial limitation form this pilot study, which is the difficulty to properly assess common adverse events (dry mouth, drowsiness, dizziness, etc.) associated with TDS application in the neurosurgical setting. Therefore, our results need to be interpreted with caution and new prospective, control-group and randomized trials are needed to address these limitations.

\section{Conclusion}

The primary efficacy of the study was to determine the efficacy and safety of using a prophylactic triple therapy with TDS, ondansetron, and dexamethasone to prevent PONV. Our data showed a PONV incidence of $33 \%$ and accumulative incidence of nausea and vomiting of $38 \% 120 \mathrm{~h}$ after surgery. In addition, our results showed that the triple therapy regimen used in this study may be an efficient alternative regimen for PONV prophylaxis in subjects undergoing neurological surgery with general anesthesia. Further studies using regimens affecting different receptor pathways should be performed to better prove the efficacy in preventing PONV. 


\section{References}

1. Gan TJ, Diemunsch P, Habib AS, Kovac A, Kranke P, Meyer TA, et al. Consensus guidelines for the management of postoperative nausea and vomiting. Anesth Analg (2014) 118(1):85-113. doi:10.1213/ANE.0000000000000002

2. Novartis Consumer Health, Inc. Parsippany, NJ (2006) [cited 2015 April 20]. Available from: http://www.baxter.com.sg/downloads/healthcare professionals/products/transdermScopPI.pdf

3. Rosner MJ, Coley IB. Cerebral perfusion pressure, intracranial pressure, and head elevation. J Neurosurg (1986) 65(5):636-41. doi:10.3171/jns.1986.65.5. 0636

4. Habib AS, Keifer JC, Borel CO, White WD, Gan TJ. A comparison of the combination of aprepitant and dexamethasone versus the combination of ondansetron and dexamethasone for the prevention of postoperative nausea and vomiting in patients undergoing craniotomy. Anesth Analg (2011) 112(4):813-8. doi:10. 1213/ANE.0b013e3181ff47e2

5. Latz B, Mordhorst C, Kerz T, Schmidt A, Schneider A, Wisser G, et al. Postoperative nausea and vomiting in patients after craniotomy: incidence and risk factors: clinical article. J Neurosurg (2011) 114(2):491-6. doi:10.3171/2010.9. JNS10151

6. Fabling JM, Gan TJ, El-Moalem HE, Warner DS, Borel CO. A randomized, double-blinded comparison of ondansetron, droperidol, and placebo for prevention of postoperative nausea and vomiting after supratentorial craniotomy. Anesth Analg (2000) 91(2):358-61. doi:10.1097/00000539-200008000-00023

7. Fabling JM, Gan TJ, Guy J, Borel CO, el-Moalem HE, Warner DS. Postoperative nausea and vomiting: a retrospective analysis in patients undergoing elective craniotomy. J Neurosurg Anesthesiol (1997) 9(4):308-12. doi:10.1097/ 00008506-199710000-00003

8. Apfel CC, Läärä E, Koivuranta M, Greim CA, Roewer N. A simplified risk score for predicting postoperative nausea and vomiting: conclusions from crossvalidations between two centers. Anesthesiology (1999) 91(3):693-700. doi:10. 1097/00000542-199909000-00022

9. Feng PH, Chu KS, Lu IC, Shieh JP, Tzeng JI, Ho ST, et al. Haloperidol plus ondansetron prevents postoperative nausea and vomiting in patients undergoing laparoscopic cholecystectomy. Acta Anaesthesiol Taiwan (2009) 47(1):3-9. doi:10.1016/S1875-4597(09)60013-8

10. Gan TJ, Sinha AC, Kovac AL, Jones RK, Cohen SA, Battikha JP, et al. A randomized, double-blind, multicenter trial comparing transdermal scopolamine plus ondansetron to ondansetron alone for the prevention of postoperative nausea and vomiting in the outpatient setting. Anesth Analg (2009) 108(5):1498-504. doi:10.1213/ane.0b013e31819e431f

11. Habib AS, Gan TJ. Combination therapy for postoperative nausea and vomiting - a more effective prophylaxis? Ambul Surg (2001) 9(2):59-71. doi:10.1016/ S0966-6532(01)00103-2

12. Habib A, El-Moalem H, Gan T. The efficacy of the 5-HT3 receptor antagonists combined with droperidol for PONV prophylaxis is similar to their combination with dexamethasone. A meta-analysis of randomized controlled trials. Can J Anesth (2004) 51(4):311-9. doi:10.1007/BF03018234

13. Macario A, Weinger M, Carney S, Kim A. Which clinical anesthesia outcomes are important to avoid? The perspective of patients. Anesth Analg (1999) 89(3):652. doi:10.1213/00000539-199909000-00022

14. Audibert G, Vial V. [Postoperative nausea and vomiting after neurosurgery (infratentorial and supratentorial surgery)]. Ann Fr Anesth Reanim (2004) 23(4):422-7. doi:10.1016/j.annfar.2004.01.005

15. Lee HK, Lee JH, Chon SS, Ahn EK, Kim JH, Jang YH. The effect of transdermal scopolamine plus intravenous dexamethasone for the prevention of postoperative nausea and vomiting in patients with epidural PCA after major orthopedic surgery. Korean J Anesthesiol (2010) 58(1):50-5. doi:10.4097/kjae.2010.58.1.50
16. Lee JS, Costantino M, McCullough MF, Lee JB, Jones MM, Carter EA, et al. Transdermal scopolamine patch with odansetron for the control of nausea after uterine artery embolization compared with odansetron alone: results of a randomized placebo-controlled trial. J Vasc Interv Radiol (2010) 21(7):1018-23. doi:10.1016/j.jvir.2010.02.035

17. Lipp A, Kaliappan A. Focus on quality: managing pain and PONV in day surgery. Curr Anaesth Crit Care (2007) 18(4):200-7. doi:10.1016/j.cacc. 2007.07.013

18. Sah N, Ramesh V, Kaul B, Dalby P, Shestak K, Vallejo MC. Transdermal scopolamine patch in addition to ondansetron for postoperative nausea and vomiting prophylaxis in patients undergoing ambulatory cosmetic surgery. J Clin Anesth (2009) 21(4):249-52. doi:10.1016/j.jclinane.2008.08.017

19. Einarsson JI, Audbergsson BO, Thorsteinsson A. Scopolamine for prevention of postoperative nausea in gynecologic laparoscopy, a randomized trial. J Minim Invasive Gynecol (2008) 15(1):26-31. doi:10.1016/j.jmig.2007.08.616

20. Jones S, Strobl R, Crosby D, Burkard JF, Maye J, Pellegrini JE. The effect of transdermal scopolamine on the incidence and severity of postoperative nausea and vomiting in a group of high-risk patients given prophylactic intravenous ondansetron. AANA J (2006) 74(2):127-32.

21. Pergolizzi JV Jr, Philip BK, Leslie JB, Taylor R Jr, Raffa RB. Perspectives on transdermal scopolamine for the treatment of postoperative nausea and vomiting. J Clin Anesth (2012) 24(4):334-45. doi:10.1016/j.jclinane.2011.07.019

22. Renner UD, Oertel R, Kirch W. Pharmacokinetics and pharmacodynamics in clinical use of scopolamine. Ther Drug Monit (2005) 27(5):655-65. doi:10.1097/ 01.ftd.0000168293.48226.57

23. Nachum Z, Shupak A, Gordon CR. Transdermal scopolamine for prevention of motion sickness. Clin Pharmacokinet (2006) 45(6):543-66. doi:10.2165/ 00003088-200645060-00001

24. Antor MA, Uribe AA, Erminy-Falcon N, Werner JG, Candiotti KA, Pergolizzi JV, et al. The effect of transdermal scopolamine for the prevention of postoperative nausea and vomiting. Front Pharmacol (2014) 5:55. doi:10.3389/fphar. 2014.00055

25. Harnett MJ, O’Rourke N, Walsh M, Carabuena JM, Segal S. Transdermal scopolamine for prevention of intrathecal morphine-induced nausea and vomiting after cesarean delivery. Anesth Analg (2007) 105(3):764-9. doi:10.1213/01.ane. 0000277494.30502.db

26. Manninen PH, Raman SK, Boyle K, el-Beheiry H. Early postoperative complications following neurosurgical procedures. Can J Anesth (1999) 46(1):7-14. doi:10.1007/BF03012507

27. Antor M, Puente EG, Portillo JG, Uribe AA, Bergese SD. Studying the effectiveness of triple therapy with scopolamine, ondansetron and dexamethasone for prevention of post operative nausea and vomiting in high risk patients undergoing neurological surgery and general anesthesia. J Clin Trials (2012) 2:108. doi:10.4172/2167-0870.1000108

28. Sanger GJ, Andrews PL. Treatment of nausea and vomiting: gaps in our knowledge. Auton Neurosci (2006) 129(1):3-16. doi:10.1016/j.autneu.2006.07.009

Conflict of Interest Statement: The authors declare that the research was conducted in the absence of any commercial or financial relationships that could be construed as a potential conflict of interest.

Copyright (c) 2015 Bergese, Antor, Uribe, Yildiz and Werner. This is an open-access article distributed under the terms of the Creative Commons Attribution License (CC $B Y)$. The use, distribution or reproduction in other forums is permitted, provided the original author(s) or licensor are credited and that the original publication in this journal is cited, in accordance with accepted academic practice. No use, distribution or reproduction is permitted which does not comply with these terms. 